\title{
Consequences of Influence Tactics Used With Subordinates, Peers, and the Boss
}

\author{
Gary Yukl* \\ School of Business \\ State University of New York at Albany \\ 1400 Washington Ave. \\ Albany, NY 12222 \\ J. Bruce Tracey \\ School of Business \\ State University of New York at Albany \\ 1400 Washington Ave. \\ Albany, NY 12222
}

* Corresponding author

Published in: Journal of Applied Psychology (1992), Vol. 77, No.

$4,525-535$ 


\section{Abstract}

A field study was conducted to discover how a manager's use of nine different influence tactics is related to target task commitment and the manager's effectiveness. The variables were measured with a questionnaire filled out by subordinates, peers, and the boss of each manager. The most effective tactics were rational persuasion, inspirational appeal, and consultation; the least effective were pressure, coalition, and legitimating. Ingratiation and exchange were moderately effective for influencing subordinates and peers but were not effective for influencing superiors. Inspirational appeal, ingratiation, and pressure were used most in a downward direction; personal appeal, exchange, and legitimating were used most in a lateral direction; coalitions were used most in lateral and upward directions; and rational persuasion was used most in an upward direction. 
Consequences of Influence Tactics Used With Subordinates, Peers, and the Boss

One of the most important determinants of managerial effectiveness is success in influencing people and developing their commitment to task objectives (Yukl, 1989). Despite the obvious importance of this subject, there has not been much empirical research on the influence behavior of managers. Several studies have examined issues such as how often various influence tactics are used by managers with different targets and for different influence objectives (Ansari \& Kapoor, 1987; Erez \& Rim, 1982; Erez, Rim, \& Keider, 1986; Kipnis, Schmidt, \& Wilkinson, 1980; Schmidt \& Kipnis, 1984; Yukl \& Falbe, 1990). Only a handful of studies have considered the relative effectiveness of different influence tactics.

Mowday (1978) investigated the relationship between the self-rated use of five influence tactics by elementary school principals and ratings made by the immediate superior of each principal on the principal's overall effectiveness in exercising influence. Only one tactic (information distortion) discriminated significantly between more and less effective principals.

Kipnis and Schmidt (1988) used profiles of scale scores on their self-report influence questionnaire to cluster managers 
into four influencer types, which were then compared with regard to performance evaluations. Kipnis and Schmidt found that shotgun managers (with high scores on assertiveness, appeal to higher authority, and coalition) received the lowest performance ratings and that tacticians (who used rational persuasion more than other tactics) received the highest performance ratings; ingratiators (who used ingratiation more than other tactics) received only a moderate performance rating.

Schilit and Locke (1982) had students interview managers to obtain descriptions of successful or unsuccessful upward influence attempts, either from the perspective of the agent (subordinate) or from the perspective of the target (boss). The influence tactics used in each incident were coded into 18 categories, and the frequency of use for each tactic was compared for successful and unsuccessful influence attempts. Few significant differences were found, and the results for these tactics were not consistent across the two samples.

A series of three studies compared successful and unsuccessful influence incidents obtained by students from interviews with managers. Influence behavior was coded into 21 tactics in a study of upward incidents (Case, Dosier, Murkinson, \& Keys, 1988), 17 tactics in a study of downward incidents (Dosier, Case, \& Keys, 1988), and 11 tactics in a study of lateral incidents (Keys, Case, Miller, Curran, \& Jones, 1987). 
Despite the large number of comparisons of successful and unsuccessful incidents in the three studies, only two differences were significant at a traditional 5\% level.

Overall, previous research provides only limited insight into the relative effectiveness of different tactics. Few findings were significant, and results were not consistent across studies. The lack of strong, consistent results from prior research on influence outcomes may be due to a number of reasons. Most of the studies examined only upward influence, in which the utility of some tactics is limited and the agent's influence is likely to be smallest. The selection and measurement of influence tactics differed substantially from study to study, as did the criteria used to evaluate tactics. None of the correlational studies used an immediate outcome, such as the target's task commitment, which is likely to be affected more by an agent's influence behavior than is a criterion such as ratings of overall agent performance. The critical incident studies used an immediate outcome but measured it in terms of a simple dichotomy (i.e., successful versus unsuccessful), which reduced the likelihood of finding any effect of influence tactics on outcomes.

The current study had two research objectives. The primary objective was to investigate the effectiveness of different influence tactics for influencing subordinates, peers, and 
superiors. Our research attempts to overcome the limitations of earlier research on tactic effectiveness by examining all three directions of influence, by including task commitment as an immediate criterion of influence success in addition to performance ratings, and by comparing a wide variety of potentially relevant influence tactics in the same study.

A secondary objective was to clarify and extend what is known about directional differences in how often various*influence tactics are used with subordinates, peers, and superiors. Three prior studies (Erez et al., 1986; Kipnis et al., 1980; Yukl \& Falbe, 1990) examined directional differences in the use of influence tactics. Fairly consistent results were found for pressure and exchange, but results were inconsistent across studies for other tactics. In the current study, we used a matched design with a large number of respondents to provide a more powerful test of directional differences than was possible in the earlier research involving a random groups design. Directional differences in tactic effectiveness and frequency of use were examined together for the first time in the same study in an attempt to integrate these previously separate lines of research.

Insert Table 1 
Tactics and Model

The study reported in this article deals with the nine influence tactics defined in Table 1. These tactics are based on results from factor analysis of questionnaires and other types of construct validation research, such as Q sorts by subjectmatter experts, interrater agreement in the coding of critical incidents, analysis of content validity, and analysis of discriminant validity (Schriesheim \& Hinkin, 1990; Yukl \& Falbe, 1990; Yukl, Lepsinger, \& Lucia, in press). The nine tactics cover a wide variety of proactive influence behaviors likely to be relevant to a manager's effectiveness in influencing others. These influence tactics have been used in prior research on influence effectiveness, but none of the prior studies included all nine of the tactics.

In our preliminary model, the following interrelated factors determine how frequently an influence tactic is used in a particular direction: (a) consistency with prevailing social norms and role expectations about use of the tactic in that context, (b) agent possession of an appropriate power base for use of the tactic in that context, (c) appropriateness for the objective of the influence attempt, (d) level of target resistance encountered or anticipated, and (e) costs of using the tactic in relation to likely benefits. The underlying 
assumption is that most agents will prefer to use tactics that are socially acceptable, that are feasible in terms of the agent's position and personal power in relation to the target, that are not costly (in terms of time, effort, loss of resources, or alienation of the target), and that are likely to be effective for a particular objective given the anticipated level of resistance by the target. We used the model to derive specific hypotheses about directional differences in the frequency of use of the nine tactics. For example, tactics such as legitimating, exchange, pressure, and ingratiation are more consistent with the power base and role expectations for a boss in relation to a subordinate than for a subordinate in relation to a boss.

In our preliminary model, the following factors determine the effectiveness of an influence tactic used by a particular agent in a particular context: (a) consistency with prevailing social norms and role expectations about the use of the tactic in that context, (b) the agent's possession of an appropriate power base for use of the tactic in that context, (c) potential of the tactic to influence the target's attitudes about the desirability of the requested action, (d) the agent's skill in using the tactic, and (e) the amount of intrinsic resistance by the target due to the nature of the request. The underlying assumption is that a tactic is more likely to be successful if 
the target perceives it to be a socially acceptable form of influence behavior, if the agent has sufficient position and personal power to use the tactic, if the tactic has the capability to affect the target's attitudes about the desirability of the request, if the tactic is used in a skillful way, and if it is used for a request that is legitimate and consistent with the target's values and needs. The model is used to derive specific hypotheses about the effectiveness of the nine tactics for influencing target commitment in a downward, lateral, or upward direction. For example, according to Kelman's (1958) theory of influence processes, tactics that are likely to cause internalization of favorable attitudes about the request (e.g., consultation, inspirational appeal, and rational persuasion) ought to be more successful than tactics that cause behavioral compliance without changing the target's attitudes. Tactics involving coercion and manipulation (e.g., pressure, legitimating, and some forms of coalition) are less socially acceptable than tactics that appeal to the target's informed judgment or to the target's friendship and identification with the agent. This set of tactics is least likely to result in target commitment.

\section{Hypotheses}

Hypotheses about the use and effectiveness of each tactic for influencing target task commitment are presented next, along 
with a rationale for each hypothesis that is based on our preliminary model and on prior research. Formal hypotheses were not made for ratings of a manager's overall effectiveness because this criterion can be affected by many things besides a manager's use of influence tactics.

Hypothesis la. Rational persuasion is used more in an upward direction than in a downward or lateral direction. Hypothesis 1b. Rational persuasion increases task commitment in all three directions.

Rational persuasion involves the use of logical arguments and factual information to convince a target that the agent's request or proposal is feasible and consistent with shared objectives (Eagly \& Chaiken, 1984). This is a flexible tactic that can be used for influence attempts in any direction. Nevertheless, rational persuasion is likely to be used more in an upward direction than in other directions, because in an upward direction a manager is limited by a weaker power base and role expectations that discourage the use of some tactics (see discussion of other hypotheses). Directional differences for the use of rational persuasion were not consistent in three prior studies conducted with questionnaires (Erez et al., 1986; Kipnis et al., 1980; Yukl \& Falbe, 1990). Agents reported greater use of this tactic in upward influence attempts, but directional differences were not found for targets. 
Results for the consequences of using rational persuasion have been inconsistent also. In the questionnaire study by Kipnis and Schmidt (1988), managers who received the highest performance ratings had a profile in which rational persuasion was the dominant tactic for upward influence attempts. However, rational persuasion was not related to successful upward influence in the questionnaire study by Mowday (1978). Likewise, tactics involving aspects of rational persuasion were not related to outcome success in the four critical incident studies described earlier.

Hypothesis 2a. Inspirational appeals are used more in a downward direction than in a lateral or upward direction. Hypothesis 2b. Inspirational appeals increase task commitment in all three directions. Inspirational appeals use the target's values, ideals, aspirations, and emotions as a basis for gaining commitment to a request or proposal (Yukl, 1990). Inspirational appeals appear feasible for influence attempts made in any direction, but this tactic is especially appropriate for gaining the commitment of someone to work on a new task or project. Influence attempts involving task assignments occur most often in a downward direction and least often in an upward direction (Erez et al., 1986; Kipnis et al., 1980; Yukl \& Falbe, 1990). Thus, managers have more opportunity to use inspirational appeals with 
subordinates than with peers or superiors. In the only prior study to examine directional differences for inspirational appeals, Yukl and Falbe (1990) found that inspirational appeals were used more in downward influence attempts than in lateral or upward influence attempts.

There is little evidence about the likely effectiveness of inspirational appeals, and this research deals only with the downward influence of leaders over subordinates. Descriptive studies of charismatic and transformational leadership (Bass, 1985; Conger, 1989; Tichy \& Devanna, 1986) have found that managers who motivate exceptional effort by subordinates present a clear and inspiring vision, which is one type of inspirational appeal .

Hypothesis 3a. Consultation is used more in a downward direction than in a lateral or upward direction. Hypothesis 3b. Consultation increases task commitment in all three directions.

When people gain a sense of ownership of a project, strategy, or change after participating in planning how to implement it, they are likely to be more committed to making the project, strategy, or change successful (Yukl, 1989). This influence tactic can be used in any direction, but it appears especially appropriate in the situation in which an agent has the authority to plan a task or project but relies on the target 
to help implement the plans. Because authority to assign work and make changes in work procedures is mostly downward, a manager probably has more opportunity to use consultation to influence subordinates than to influence peers or superiors (Yukl \& Falbe, 1990). Only one study examined directional differences in frequency of use for consultation (Yukl \& Falbe, 1990), and results were mixed. Agents reported greater use of consultation in a downward direction, but directional differences were not significant for target reports. Evidence on the likely effectiveness of consultation as an influence tactic is limited and inconsistent. Schilit and Locke (1982) found that a consultation tactic (using the target as a platform to present ideas) was likely to be effective in upward incidents reported by targets, but the results were not significant for upward incidents reported by agents in that study or in the study by case et al. (1988). In the study by Dosier et al. (1988) of downward incidents reported by agents, results for consultation tactics (listening, soliciting ideas) were not significant. Indirect evidence comes from research on leadership, which finds that that consultation with individual subordinates is effective for increasing decision acceptance in some situations but not in others (see Vroom \& Jago, 1988). Hypothesis 4a. Ingratiation is used more in a downward and lateral direction than in an upward direction. 
Hypothesis 4b. Ingratiation has a stronger positive effect on task commitment in a downward and lateral direction than in an upward direction.

The basis for influence in ingratiation is an increase in the target's feeling of positive regard toward the agent. Flattery, praise, expression of acceptance, and expression of agreement are used to increase the agent's attractiveness to the target (Li- den \& Mitchell, 1988; Tedeschi \& Melburg, 1984). A target is more likely to cooperate with an agent for whom the target has feelings of positive regard. Compliments and flattery are more credible when the status and power of the agent is greater than that of the target (Wortman \& Linsenmeier, 1977). Thus, ingratiation is most likely to increase positive regard and influence target cooperation when the agent is a superior, and it is least likely to do so when the agent is a subordinate. Findings on directional differences in the use of ingratiation are somewhat inconsistent. In the studies by Kipnis et al. (1980) and Yukl and Falbe (1990), agents reported that ingratiation was used more in downward and lateral influence attempts than in upward influence attempts. No significant directional differences were found for target reports in the study by Yukl and Falbe (1990), and no clear pattern emerged for agent and target reports in the study by Erez et al. (1986). 
Only two studies have examined the consequences of using ingratiation as a proactive influence tactic. In their questionnaire study of upward influence, Kipnis and Schmidt (1988) found that male managers whose influence profile involved a relatively high use of ingratiation received only moderate performance ratings but that female ingratiators received higher performance ratings. Outcome success was not significantly affected by ingratiation tactics (using courtesy, kind manners, or friendliness) in lateral incidents described by agents in the study by Keys et al. (1987) .

Hypothesis 5 a Exchange is used more in a downward and lateral direction than in an upward direction. Hypothesis 5b. Exchange has a stronger positive effect on task commitment in a downward and lateral direction than in an upward direction.

Exchange tactics involve explicit or implicit offers by an agent to provide a favor or benefit to the target in return for doing what the agent requests. To be effective, the agent must offer something the target considers desirable and appropriate (Yukl, 1990). Managers usually have considerable control over resources and rewards desired by subordinates. The potential for exchange with peers depends on the amount of lateral task interdependence and a manager's control over resources desired by peers. Descriptive studies have found that exchange is often 
used to obtain support and assistance from peers (see A. Cohen \& Bradford, 1989; Kaplan, 1986). Managers have little control over resources desired by superiors, and it is awkward to initiate an exchange of tangible benefits with them because it is not consistent with role expectations. Thus, there is more opportunity to use exchange with subordinates and peers than with superiors. Three prior studies (Erez et al., 1986; Kipnis et al., 1980; Yukl \& Falbe, 1990) found that exchange was used more in downward and lateral influence attempts than in upward influence attempts.

Results for the consequences of using exchange are not as clear or consistent. Schilit and Locke (1982) found that exchange (trading job-related benefits) was more likely to be successful than unsuccessful in upward critical incidents described by targets, but results for this tactic were not significant in upward incidents described by agents. No significant effects of exchange tactics (offering to trade favors or concessions) were found in the study of upward incidents by Case et al. (1988), in the study of lateral incidents by Keys et al. (1987), or in the questionnaire study by Mowday (1978) of upward influence.

Hypothesis 6a. Personal appeals are used more in a lateral direction than in a downward or upward direction. 
Hypothesis 6b. Personal appeals increase task commitment in all three directions.

Personal appeals are based on referent power already possessed by the agent (Yukl, 1990). When a target has strong feelings of friendship toward the agent, it is more likely that the agent can appeal successfully to the target to do something unusual or extra as a special favor (e.g., do some of my work, make a change to accommodate me, help me deal with a problem). This tactic appears to be most appropriate for influence attempts with peers, because managers often need to ask for favors from peers but lack the authority to ensure compliance with a formal request (Kotter, 1982). However, no prior research has been conducted on directional differences in the use of personal appeals.

Only three studies have directly examined the effectiveness of personal appeals as an influence tactic. In the critical incident study by Schilit and Locke (1982), personal appeals (asking for favors or pity) were not related to success in upward influence attempts. Likewise, in the critical incidents study by Case et al. (1988), personal appeals (pleading, begging, or asking favors) were not related to the success of upward influence attempts. In the critical incidents study by Keys et al. (1987), personal appeals (appealing to sympathy of target) were not related to the success of lateral influence 
attempts. Some indirect evidence is provided by a study that found a positive correlation between a manager's referent power and the task commitment of subordinates and peers (Yukl \& Falbe, 1991). Other power studies (see Podsakoff \& Schriesheim, 1985) have found a positive correlation between a manager's referent power and measures of subordinate satisfaction and performance. Hypothesis 7a. Coalition tactics are used more in a lateral and upward direction than in a downward direction. Hypothesis 7b. Coalition tactics are negatively related to task commitment in all three directions. With coalition tactics, an agent enlists the aid or endorsement of other people to influence a target to do what the agent wants (Stevenson, Pearce, \& Porter, 1985). There is evidence from descriptive research that managers use coalitions to influence peers and superiors to support changes, innovations, and new projects (Kanter, 1983; Kotter, 1982). Yukl and Falbe (1990) proposed that coalitions are less likely to be used in downward influence attempts, because managers usually have substantial power over subordinates, and having to ask for help to influence a subordinate may reflect unfavorably on the competence of the manager. In a study by Erez et al. (1986), agents reported that coalitions were used most often in a lateral direction. However, in two other studies with agent reports (Kipnis et al., 1980; Yukl \& Falbe, 1990) and in two 
studies with target reports (Erez et al., 1986; Yukl \& Falbe, 1990), no significant directional differences were found for use of coalition tactics.

Coalitions are used most often as a follow-up tactic after the target has already resisted a direct influence attempt by the agent (Yukl \& Falbe, 1992). Thus, use of this tactic often indicates a type of request or proposal for which target commitment is especially difficult to attain. Moreover, this tactic is likely to be viewed as manipulative by a target who is aware that the agent is using it. The most offensive form of coalition may be an upward appeal to the target's superior to pressure the target to comply with the agent s request.

Studies on the consequences of using coalition tactics have yielded inconsistent results. In the questionnaire study by Kipnis and Schmidt (1988), self-reported use of coalitions in upward influence was part of the profile for managers who received the lowest performance ratings. Only one of four critical incident studies found evidence that coalition tactics are effective. In a study by Keys et al. (1987), a lateral influence attempt was more likely to be successful when the agent used a coalition tactic (gain support of several peers to influence target). In the critical incident study by schilit and Locke (1982), coalition tactics (using group or peer support) were not significantly related to outcome success in upward 
influence attempts. Likewise, outcome success was not significantly related to use of a coalition tactic (soliciting assistance of peers) in the study of downward incidents by Dosier et al. (1988) or to use of coalition tactics (developing and showing support of peers, subordinates, or outsiders) in the study of upward incidents by case et al. (1988).

Hypothesis 8a. Legitimating tactics are used more in a lateral direction than in a downward or upward direction. Hypothesis 8b. Legitimating tactics are negatively related to task commitment in all three directions. Legitimating tactics involve efforts to verify the legitimacy of a request and the agent's authority or right to make it. This tactic is most appropriate for a request that is unusual and of doubtful legitimacy to the target person (Yukl, 1990). Legitimating tactics are needed most in a lateral direction because ambiguity about authority relationships and task responsibilities is greatest in this direction. Legitimating tactics are rarely needed in a downward direction, because most managers have considerable authority to direct the work activities of subordinates. Legitimating tactics are seldom needed in an upward direction, and they are difficult to use in this direction because of the limited basis for claiming a right to dictate the actions of a person with higher authority. 
Directional differences in use of legitimating tactics were not examined in prior research.

Legitimating tactics may induce the target to comply with a request if the target is convinced the request is within the agent's scope of authority and consistent with organizational rules and policies. Yukl and Falbe (1991) found that the most frequent reason reported by managers for complying with a request made by a superior or peer was the legitimacy of the request. However, there is little reason to expect legitimating tactics to increase task commitment, and a negative reaction by the target may occur if this kind of tactic is used in an arrogant and demanding manner (Yukl, 1989). Only a few studies have examined the consequences of using legitimating tactics. In Mowday's (1978) questionnaire study of upward influence, legitimating tactics were not correlated significantly with influence success. In the study by Schilit and Locke (1982), legitimating tactics (using organizational rules) were not related significantly to outcome success in upward influence incidents. In the study by Keys et al. (1987), legitimating tactics (calling on company policies, procedures, or rules) were not related significantly to outcome success in lateral influence incidents.

Hypothesis 9a. Pressure tactics are used more in a downward direction than in a lateral or upward direction. 
Hypothesis 9b. Pressure tactics are negatively related to task commitment in all three directions. Many pressure tactics involve the use of a manager's coercive power, which is greater in relation to subordinates than in relation to peers or superiors. Previous studies consistently find greater use of pressure in a downward direction (Erez et al., 1986; Kipnis et al., 1980; Yukl \& Falbe, 1990). Pressure may elicit reluctant compliance from a target, but it is unlikely to result in commitment. Research with critical incidents indicates that pressure is used most often as a follow-up tactic after an initial influence attempt has already failed (Yukl, Falbe, \& Youn, in press). Thus, use of this tactic often indicates a type of request or proposal for which target commitment or even compliance is difficult to attain. Moreover, in many situations pressure is viewed as an inappropriate form of influence behavior, and target resentment about an agent's use of coercion is likely to result in target resistance.

Most studies on the consequences of influence tactics have found either a negative or nonsignificant correlation between pressure and the success of an influence attempt. In the study by Kipnis and Schmidt (1988), self-reported use of pressure was a key part of the profile for managers who received the lowest performance ratings. In the study by Schilit and Locke (1982), 
targets reported that some pressure tactics used in upward influence attempts (threatening to go over target's head, challenging the power of the target) were likely to be unsuccessful. In the same study, agents reported that another pressure tactic (threatening to resign) was likely to be unsuccessful. In the study by Case et al. (1988), an upward influence attempt was likely to be unsuccessful when the agent used a pressure tactic (telling or arguing without support). In the study by Dosier et al. (1988) of downward critical incidents, there was a marginally significant $(p<.10)$ negative relationship between pressure tactics (threatening, warning, reprimanding, or embarrassing) and the success of an influence attempt. In two other studies (Keys et al., 1987; Mowday, 1978) results for the effects of pressure were not significant. Research on the use of coercive power by managers (see Podsakoff \& Schriesheim, 1985; Yukl \& Falbe, 1991) provides indirect evidence that pressure tactics are unlikely to result in target commitment.

Method

Sample

The study was conducted with respondents from five large companies: a pharmaceuticals company, a chemicals and 
manufacturing company, a financial services company, and two insurance companies. Each manager who volunteered to participate in a management development workshop conducted by a consulting company was asked several weeks before the workshop to distribute questionnaires (with a cover letter) to his or her boss and 10 other people (peers and subordinates) who had known the manager for at least 6 months. Because questionnaire data would be used to provide feedback to the managers in the workshop, they were encouraged to select a representative set of subordinates and several peers with whom they interacted frequently.

Subordinate and peer respondents were anonymous. They were assured that their individual responses would remain confidential and that only a composite summary of the influence tactic scores based on their responses would be seen by the managers participating in the workshops. The boss of each focal manager was informed that his or her responses to the influence tactics questionnaire would be seen by the manager and would not be anonymous. All respondents were informed that the ratings of task commitment and effectiveness were for research purposes only and would not be seen by the manager or anyone else in the company. Each respondent returned the questionnaire directly to the consulting company in a self-addressed, stamped envelope provided for that purpose. Demographic information was obtained 
directly from the focal managers with a supplementary questionnaire administered prior to the workshop.

A manager was included in the final data set only if questionnaires were received from the manager's boss and at least three peers and three subordinates. This requirement was imposed to avoid using managers who may have selected only a few close friends who they knew would provide especially favorable ratings. The final sample included 128 managers and the people who rated them on the questionnaires. The respondents included 526 subordinates, 543 peers, and 128 superiors. The number of subordinate and peer respondents describing each manager ranged from 6 to 10, with a median of 8. Half of the managers were in manufacturing companies, and half were in service companies. Looking at the distribution by management level, 24\% were upper level managers, 62\% were middle managers or managers of professionals, and 14\% were supervisors. The median span of control was 6 subordinates (direct reports). The average age of the managers was 40 years, and 71\% of the managers were men. Most of the managers (68\%) had been in their current job longer than a year. Demographic information was not available for the target respondents because questions that could be used to identify individual subordinates and peers were not asked in order to guarantee anonymity. 
Measures

Influence tactics were measured with the 1990 version of the Influence Behavior Questionnaire (IBQ) developed by Yukl and his colleagues (Yukl et al., in press). The IBQ has scales measuring the nine influence tactics listed in Table 1. Each scale had from three to six items with the following response choices:

1. I cannot remember him/her ever using this tactic with me.

2. He/she very seldom uses this tactic with me.

3. He/she uses this tactic occasionally with me.

4. He/she uses this tactic moderately often with me.

5. He/she uses this tactic very often with me. Sample items and a description of the developmental research can be found in the report by Yukl et al. (in press). The questionnaire also included two items measuring conceptually distinct but important criteria for evaluating the influence behavior of a manager. One item asked how many influence attempts by the agent resulted in complete commitment by the target respondent (i.e., strong enthusiasm and special effort beyond what is normally expected). There were seven response choices:

1. None of them.

2. A few of them.

3. Some (less than half). 
4. About half of them.

5. More than half of them,

6. Most of them.

7. All of them.

A second item asked the respondent to rate the overall

effectiveness of the influence agent (manager) in carrying out his or her job responsibilities. This item had nine response choices:

1. The least effective manager I have known.

2. Well below average, in the bottom $10 \%$

3. Moderately below average, in the bottom $40 \%$.

4. A little below average, in the bottom $40 \%$.

5. About average in effectiveness.

6. A little above average, in the top $40 \%$.

7. Moderately above average, in the top $25 \%$

8. Well above average, in the top $10 \%$

9. The most effective manager I have ever known.

Results

The data analyses and results are described in four separate sections: reliability and validity of measures, directional differences in use of tactics, relation of tactics 
to task commitment, and relation of tactics to effectiveness ratings .

Reliability and Validity of Measures

As in the earlier study by Yukl and Falbe (1990), internal consistency was satisfactory for most of the IBQ scales. The alpha coefficients for the combined sample of all respondents are shown in Table 2. Results were similar when calculated separately for subordinates, peers, and bosses. Internal consistency was lowest for the two scales with only three items (Personal Appeal and Ingratiation).

Some of the IBQ scale scores were moderately correlated for the sample used in the current study (see Table 2). Factor analyses of data from this sample and earlier studies suggest that the nine tactics are distinct forms of influence behavior. Research with critical incidents (Yukl et al., in press) revealed that some tactics $(e . g \cdot$, rational persuasion and consultation) are used together in the same influence attempt fairly often, which may account for the moderate correlation among the IBQ scales measuring these tactics. Nevertheless, the descriptive research also indicates that each of the tactics is used alone in some influence attempts, supporting our decision to treat them as distinct forms of behavior. 
There was a moderate degree of interrater agreement among sets of respondents describing the same manager. A one-way analysis of variance for the 128 managers yielded eta coefficients ranging from .59 to .71 for subordinates and from .54 to .65 for peers. Stability for all of the scales was found to be moderately high in previous validation research by Yukl et al. (in press).

Internal consistency could not be assessed for the singleitem criterion measures, but stability for the two items was found to be high in a pi lot study of 45 master's-level students in business administration who had regular day jobs. Respondents were anonymous but provided a code number to allow matching of the two sets of ratings. Over a 5-week interval, the test-retest correlation was .74 for task commitment and .90 for managerial effectiveness. Additional evidence for the validity of the effectiveness ratings is provided by the moderately high level of interrater agreement; the rating made by a manager's boss correlated .54 with the composite rating obtained from the manager's peers and subordinates.

Directional Differences in Use of Tactics

Directional differences in the use of the influence tactics were evaluated with a multivariate analysis of variance (MANOVA). The M ANOVA for the nine tactics yielded highly 
significant results on Wilks's lambda test, $F(18,2356)=24.5, p<$ .01. The means and standard deviations for the tactics are shown in Table 3, along with the results of the univariate $F$ tests. Significant directional differences were found for eight of the nine tactics. Despite the moderate intercorrelation among some tactics, most of these tactics had a unique pattern of directional differences, which supports our decision to treat the nine tactics as distinct forms of influence behavior.

Insert Table 2

Pairwise comparisons were assessed with Duncan's multiplerange test. Complete or partial support was found for all of the directional hypotheses except Hypothesis $3 a$ (involving consultation). Consistent with Hypothesis la, rational persuasion was used most in an upward direction. Consistent with Hypotheses $2 \mathrm{a}$ and 9a, inspirational appeal and pressure were used most in a downward direction. Consistent with Hypothesis 4a, ingratiation was used less in an upward direction than in a lateral or downward direction. Partially consistent with Hypothesis 5a, exchange was used most in a lateral direction and least in an upward direction. Consistent with Hypothesis 7a, coalition was used least in a downward direction. The current 
study is the first to examine directional differences for personal appeal and legitimating tactics, and consistent with Hypotheses $6 \mathrm{a}$ and $8 \mathrm{a}$, these tactics were used most in a lateral direction. The squared eta values in Table 3 indicate that direction of influence accounted fora relatively small percentage of the variance in use of tactics.

Insert Table 3

Relation of Tactics to Task Commitment

The correlation of each influence tactic with the target's task commitment is shown in Table 4. For this criterion, all analyses were conducted at the individual level because data on the predictors and criterion were from the same respondents. Because of the large number of variables and the much greater number of subordinate and peer respondents than of boss respondents, a conservative .01 significance level was used for testing the significance of correlations in the two large samples. Hypothesized directional differences in tactic effectiveness were evaluated by making pairwise comparisons of the correlation coefficients for the relevant subsamples. The 
difference between each pair of correlations was evaluated with Fisher's Z transformation (J. Cohen \& Cohen, 1983). Consistent with Hypotheses 1b, 2b, and 3b, rational persuasion, inspirational appeal, and consultation by the agent were correlated significantly with target's task commitment in all three directions. Consistent with Hypotheses 4b and 5b, agent ingratiation and exchange correlated significantly with task commitment for subordinates and peers, and each of these correlations was significantly larger $(p<.01)$ than the corresponding (nonsignificant) correlation for upward influence. Hypothesis $6 \mathrm{~b}$ was partially supported; personal appeal correlated significantly with task commitment for subordinates and peers but not for superiors. No directional differences were expected for personal appeal, and the pairwise differences among correlations were not significant for this tactic. Hypothesis 7b was not supported, but the results are consistent with the interpretation that coalition tactics were not effective for influencing task commitment in any direction. Partial support was found for Hypothesis 8b; legitimating tactics correlated negatively with task commitment for peers. Partial support was found for Hypothesis 9b; pressure was negatively correlated with task commitment for subordinates and peers. Directional differences were not expected for legitimating tactics or 
pressure, and the pairwise differences in correlations were not significant for these two tactics.

Interpretation of the results is complicated by the moderately high correlation among some tactics. A multiple regression analysis was conducted to examine the relationship between each tactic and task commitment after controlling for correlations among the tactics. For downward influence, the tactics of inspirational appeal, consultation, and pressure had significant beta weights (the beta for pressure was negative), and together these three tactics accounted for 33\% of the variance in the task commitment of subordinates $(R=.58)$, $F(9,504)=27.9, p<.01$. For lateral influence, the tactics of inspirational appeal, consultation, rational persuasion, exchange, coalition, and legitimating had significant beta weights (those for coalition and legitimating were negative), and together these six tactics accounted for 36\% of the variance in the task commitment of peers $(R=.61), F(9,523)=34.6, p<.01$. For upward influence, the tactics of rational persuasion and inspirational appeal had significant beta weights, and these two tactics accounted for 33\% of the variance in the task commitment of superiors $(R=.58), F(9,119)=6.4, p<.01$.

The multiple regression analyses showed that even the most highly intercorrelated tactics may account for unique variance in target commitment, and this finding provides additional 
support for our assumption that the nine tactics are distinct forms of influence behavior. The results varied more across the three samples for the regression analyses than for the simple correlations, but in general the most effective tactics were still rational persuasion, inspirational appeal, and consultation, and the least effective tactics were still coalition, pressure, and legitimating. Compared with results from the correlational analyses, results in the multiple regression analyses were weaker for ingratiation, exchange, and personal appeal.

Insert Table 4

Relation of Tactics to Effectiveness Ratings

The correlations between influence tactics and the ratings of effectiveness made by a manager's boss are also shown in Table 4. For analyses involving upward influence, data on influence tactics and managerial effectiveness were obtained from the same source, namely, the manager's boss. For downward influence, the group mean score on each influence tactic was computed for a manager's subordinates and correlated with the effectiveness rating made by the manager's boss. For lateral influence, the group mean score on each influence tactic was computed for a manager's peers and correlated with the 
effectiveness rating made by the manager's boss. Use of grouplevel analysis is consistent with the moderately high level of interrater agreement found for each tactic within the subordinate sample and the peer sample. Results for the correlations were similar in all three directions. Effectiveness ratings were correlated positively with a manager's use of rational persuasion, inspirational appeal, and consultation. Correlations for the remaining tactics were negative or nonsignificant.

As was done for task commitment, a multiple regression analysis was conducted for each sample. Only rational persuasion had a significant beta weight in the regression analyses for subordinates and peers. A manager's use of rational persuasion with subordinates accounted for 18\% of the variance in boss ratings of the manager's effectiveness $(R=.43), F(9,119)=3.0, p<$ .01. A manager's use of rational persuasion with peers accounted for $15 \%$ of the variance in effectiveness ratings made by the manager's boss $(R=.39), F(9,119)=2.4, p<.05$. For the sample of boss respondents, a manager's use of rational persuasion and inspirational appeals accounted for $34 \%$ of the variance in effectiveness ratings $(R=.59), \quad F(9,119)=6.9, p<.01$. 
Previous research provides no clear indication of the tactics likely to be effective for influencing subordinates, peers, and managers. The current study yielded stronger results, and these results appear consistent with theory and behavioral research in other topic areas, such as leadership, motivation, attitude change, and conflict resolution. The results supported most of the hypotheses about the likely effectiveness of each tactic for influencing target task commitment.

In general, consultation, inspirational appeal, and rational persuasion were moderately effective for influencing task commitment, regardless of direction. These three tactics all involve an attempt to change the target's attitude about the desirability of the request, and the tactics are likely to be viewed as socially acceptable for influence attempts in all three directions.

Pressure, coalition, and legitimating were usually ineffective. The negative correlations between these tactics and target commitment probably reflects their frequent use in influence attempts when resistance is anticipated or has already occurred in an earlier influence attempt. In addition, these tactics are likely to be viewed as socially undesirable forms of influence behavior in many situations, and the target may become resentful or angry with the agent for trying to coerce or manipulate him or her. 
Ingratiation and exchange were moderately effective for influencing subordinates and peers, but these two tactics were ineffective for influencing superiors. Agents have a weak power base from which to use these tactics in an upward direction, and they are likely to be viewed as manipulative in this context. Ingratiation is more effective when used as part of a long-term strategy for improving upward relations, rather than as a tactic for immediately influencing a superior.

Personal appeals also appeared to be moderately effective for influencing subordinates and peers, but the results for this tactic were weak and difficult to interpret. The weak results may reflect the relatively low reliability of this scale in the current study. The questionnaire will be revised in subsequent research to increase the number of items for personal appeals and ingratiation.

Fewer tactics were correlated significantly with ratings of managerial effectiveness than with task commitment, but the three tactics that correlated most strongly with task commitment also correlated consistently with effectiveness ratings. Regardless of direction, rational persuasion was clearly the best predictor of effectiveness ratings made by a manager's boss. The strong correlation between rational persuasion and effectiveness ratings may be due to a close association between a manager's skillful use of rational persuasion and rater 
perception of manager expertise. Because perception of a manager's expertise is a strong predictor of effectiveness ratings (Podsakoff \& Schriesheim, 1985; Yukl \& Falbe, 1991), it is not surprising that skillful use of rational persuasion (which requires considerable expertise) also correlated strongly with effectiveness ratings.

In general, the findings in the current study are consistent with the explanation proposed earlier for weak and inconsistent findings in the six prior studies, namely, the focus on upward influence and the use of weak criteria. Results for most tactics were weaker for upward influence attempts than for downward or lateral influence attempts. Likewise, most of our results were weaker when the criterion was a rating of managerial effectiveness rather than task commitment. We expected to find stronger results for target task commitment than for effectiveness ratings because the latter criterion is determined by many factors besides agent influence behavior. However, another possible explanation of stronger results for task commitment is use of the same respondent to provide information about the predictors and the criterion. The results for task commitment (and for effectiveness ratings in an upward direction) may be inflated somewhat by respondent biases or attributions. 
Directional differences in frequency of use were found for all of the tactics except consultation. The directional differences were consistent with hypotheses based on an analysis of working relationships that exist in most organizations for managers and their subordinates, peers, and bosses. The greater number of significant directional differences found in this study than in the study by Yukl and Falbe (1990) is probably due to our use of large samples and a matched design in which the same focal managers were described by subordinates, peers, and bosses. In earlier studies on directional differences, each sample of respondents described a different set of focal managers, and only Kipnis et al. (1980) used a large sample. Even though most directional differences were significant, they accounted for only a small proportion of the variance in the measure of tactics. As Yukl and Falbe (1990) found, the relative frequency of use for the tactics was similar in all three directions. Thus, direction does not appear to be a very important determinant of tactic selection in comparison with other factors. Overall, there was a moderate correspondence between effectiveness and frequency of use; effective tactics tended to be used more often in all directions. The reasons why managers select particular tactics should be examined more closely in future research. 
Our study has some limitations that need to be acknowledged. First, because influence behavior was not manipulated, causality can only be inferred from the results. The correlations may have been influenced by a variety of extraneous factors, such as differences in measurement accuracy among tactics, reverse causality, and respondent biases and attributions. Second, descriptions of an agent's influence behavior by targets may be insensitive to subtle forms of influence (e.g., use of deception or information distortion, some forms of coalition) that are successful only if the target is not aware they are being used. Third, results for directional differences may be biased by differences in target sensitivity to agent use of tactics that are inconsistent with role expectations (e.g., a manager may be more likely to notice and remember the use of pressure by a subordinate than by a superior). Fourth, the sampling of respondents was not random because the focal managers selected the peers and subordinates who would describe their influence behavior. However, the large number of respondents who described each manager was expected to minimize any problems due to possible bias in respondent selection. Fifth, the use of task commitment as the only immediate criterion of influence effectiveness precluded evaluation of the extent to which pressure, coalition, and legitimating may be useful for eliciting compliance. Sometimes 
compliance is all that is needed to accomplish a task objective (Yukl, 1989).

Our research findings have implications for improving managerial effectiveness because it is an advantage for a manager to know which tactics have the highest likelihood of success for influencing a subordinate, peer, or superior. However, because of the limitations of the study, caution is needed in offering guidelines until the results are verified in follow-up research with different methods and samples. The findings indicate that some tactics are more likely to be successful, but the results do not suggest that these tactics will always result in task commitment. The outcome of any particular influence attempt is determined by many factors besides influence tactics, and any tactic can result in target resistance if it is not appropriate for the situation or is used in an unskillful manner.

In summary, the findings provide some important insights into the effective use of influence tactics by managers, but additional research is needed to verify and extend the findings. More developmental research is needed to refine the IBQ scales and improve reliability and discriminant validity. In future research, it is desirable to identify when the various tactics are likely to result in target compliance rather than commitment. The scope of the research should be extended beyond 
examination of individual tactics to identify the effects of using multiple tactics at the same time and in different sequences. The contextual determinants of tactic selection and tactic outcomes in our preliminary model need to be investigated more directly. Finally, research with experimental designs is needed to verify the effect of influence tactics on outcomes. 
Table 1. Definition of influence tactics.

Tacte $\quad$ Definition

Rational persuasion

Inspirational appeal

Consultainon

Ingratuation

Exchange

Personal appeal

Coalition

Lepitimating

Pressufe
The person use logeal argumenis and factual evidence to persuade you that a proposal of request is vable and likely to result in the attainment of tave objectives.

The person makes a request or proposal that arouses enthusiasn by appealing to your values, ideals, and aspiratsons or by increasine your confidence that you can do it.

The person seeks your participation in planning a strategy. activity. or change for which you suppon and assistance are desired, or the person is willing to modify a proposal to desl with your concerns and supgestion.

The perion seeks to get you in a good mood or to think favorably of ham or her before asking you to do something.

The person offers an exchange of fawors indicates willingness to reciprocate at a laier time or promises you a share of the benefits if you help accomplish a tack.

The person appeals to your feelings of loyaliy and friendship toward him or her before asking you to do something.

The person seeks the aid of others to persuade you to do something or uses the support of others as a reason for you to agree also.

The person seeks to establish the legitimacy of a request by claiming the authority or right to make it or by werifying that it is consistent with organizational policies, rules. practices, or traditions.

The person uses demands. threats, or persistent reminders to influence you to do what he or she wants. 
Table 2. Intercorrelation of influence tactics.

\begin{tabular}{|c|c|c|c|c|c|c|c|c|c|}
\hline Tactic & 1 & 2 & 3 & 4 & 5 & 6 & 7 & 8 & 9 \\
\hline I. Rational persuasion & $(78)$ & & & & & & & & \\
\hline 2. Inspirational appeal & 55 & (B) & & & & & & & \\
\hline 3. Consultation & 60 & 58 & (BS) & & & & & & \\
\hline 4. Ingratiation & 33 & 54 & 48 & $(.65)$ & & & & & \\
\hline 5. Exchange & 31 & 42 & 33 & .50 & $(76)$ & & & & \\
\hline 6. Personal appeal & 29 & 41 & 32 & .54 & .55 & $(.55)$ & & & \\
\hline 7. Coalition & 27 & 17 & .16 & .26 & 44 & 46 & {$[.68)$} & & \\
\hline 8. Leqitimating & 16 & 08 & 02 & 27 & 35 & 42 & 63 & $(78)$ & \\
\hline 9. Pressure & 04 & 07 & -03 & .11 & .19 & 33 & 41 & 44 & (89) \\
\hline
\end{tabular}

Note. Alpha coefficients are in parentheses. 
Table 3. Means and standard deviations of influence tactics, broken down by direction.

\begin{tabular}{|c|c|c|c|c|c|}
\hline \multirow[b]{2}{*}{ Tactic } & \multicolumn{3}{|c|}{ Direction } & \multirow[b]{2}{*}{$F(2,1195)$} & \multirow[b]{2}{*}{$n^{2}$} \\
\hline & Downward & Lateral & Upward & & \\
\hline \multicolumn{6}{|c|}{ Rational persuasion } \\
\hline $\begin{array}{l}M \\
S D\end{array}$ & $\begin{array}{l}3.19 \\
0.72\end{array}$ & $\begin{array}{l}3.31 \\
0.71\end{array}$ & $\begin{array}{l}3.72 \\
0.63\end{array}$ & $30.5 * *$ & .05 \\
\hline \multicolumn{6}{|c|}{ Inspirational appeal } \\
\hline $\begin{array}{l}M \\
S D\end{array}$ & $\begin{array}{l}3.05 \\
0.87\end{array}$ & $\begin{array}{l}2.83 \\
0.87\end{array}$ & $\begin{array}{l}2.82 \text { o } \\
0.83\end{array}$ & $9.3^{\cdots *}$ & .02 \\
\hline \multicolumn{6}{|l|}{ Consultation } \\
\hline $\begin{array}{l}M \\
S D\end{array}$ & $\begin{array}{l}3.37 \\
0.82\end{array}$ & $\begin{array}{l}3.25 \\
0.84\end{array}$ & $\begin{array}{l}3.34 \\
0.76\end{array}$ & 2.9 & .00 \\
\hline \multicolumn{6}{|l|}{ Ingratiation } \\
\hline $\begin{array}{l}M \\
S D\end{array}$ & $\begin{array}{l}2.77 \\
0.93\end{array}$ & $\begin{array}{l}2.67 \mathrm{~b} \\
0.91\end{array}$ & $\begin{array}{l}2.28 \\
0.90\end{array}$ & $15.23^{* *}$ & .03 \\
\hline \multicolumn{6}{|l|}{ Exchange } \\
\hline $\begin{array}{l}M \\
S D\end{array}$ & $\begin{array}{l}1.55 \\
0.59\end{array}$ & $\begin{array}{l}1.71 \\
0.62\end{array}$ & $\begin{array}{l}1.41 \mathrm{t} \\
0.53\end{array}$ & $17,7^{* \bullet}$ & .03 \\
\hline \multicolumn{6}{|c|}{ Personal appeal } \\
\hline $\begin{array}{l}M \\
S D\end{array}$ & $\begin{array}{l}2.10 \mathrm{~b} \\
0.75\end{array}$ & $\begin{array}{l}2.23 \\
0.78\end{array}$ & $\begin{array}{l}1.97 \mathrm{e} \\
0.80\end{array}$ & $8.4^{* \bullet}$ & .01 \\
\hline \multicolumn{6}{|l|}{ Coalition } \\
\hline $\begin{array}{l}M \\
S D\end{array}$ & $\begin{array}{l}1.75 \\
0.58\end{array}$ & $\begin{array}{l}2.08 \\
0.73\end{array}$ & $\begin{array}{l}1.93 \mathrm{~b} \\
0.64\end{array}$ & $33.6 * 4$ & .05 \\
\hline \multicolumn{6}{|l|}{ Legitimating } \\
\hline $\begin{array}{l}M \\
S D\end{array}$ & $\begin{array}{l}2.31_{\mathrm{b}} \\
0.83\end{array}$ & $\begin{array}{l}2.43 \\
0.87\end{array}$ & $\begin{array}{l}2.31 \mathrm{~b} \\
0.91\end{array}$ & $3.2^{*}$ & .01 \\
\hline \multicolumn{6}{|l|}{ Pressure } \\
\hline $\begin{array}{l}M \\
S D\end{array}$ & $\begin{array}{l}2.10 \\
0.82\end{array}$ & $\begin{array}{l}1.84 \\
0.78\end{array}$ & $\begin{array}{l}1.85_{b} \\
0.80\end{array}$ & $16.2^{\bullet \bullet}$ & .03 \\
\hline
\end{tabular}

Note. Within rows, different subscripts indicate significant pairwise differences for means on Duncan's multiplerange test.

$\star p<.05 \quad * \star p<.01$ 
Table 4. Correlation of influence tactics with targets' task commitment and ratings of the agents managerial effectiveness.

\begin{tabular}{|c|c|c|c|c|c|c|}
\hline \multirow[b]{2}{*}{ Tactic } & \multicolumn{3}{|c|}{ Targets' task commitment } & \multicolumn{3}{|c|}{ EHectiveness rating } \\
\hline & $\begin{array}{c}\text { Downsard } \\
(n-526)\end{array}$ & $\begin{array}{c}\text { Lateral } \\
(n=543)\end{array}$ & $\begin{array}{c}\text { Upward } \\
(n=128)\end{array}$ & $\begin{array}{c}\text { Downward } \\
(n=128)\end{array}$ & $\begin{array}{c}\text { Laleral } \\
(n=128)\end{array}$ & $\begin{array}{c}\text { Upward } \\
{[n=128]}\end{array}$ \\
\hline Rational persuasion & $38+$ & $.43^{* \%}$ & $50^{*}$ & $39=$ & $.33^{* *}$ & $.44^{* *}$ \\
\hline Inspirational appeal & $51 \%$ & $52^{* *}$ & $33^{*}$ & $20^{\circ}$ & $19^{*}$ & $29 * *$ \\
\hline Consuliation & $42^{* 4}$ & $47^{* *}$ & $26^{4}$ & $.26^{*}$ & $.24^{* *}$ & $21^{*}$ \\
\hline Ingratiation & $34 * *$ & $31^{* *}$ & -01 & -.01 & 08 & -05 \\
\hline Exchanpe & $.26^{*}$ & $25^{* *}$ & -.04 & 10 & 07 & -.09 \\
\hline Personal appeal & $.15 *$ & $19 * *$ & 00 & 03 & 01 & -.13 \\
\hline Coalition & 00 & -.09 & -.03 & 04 & 03 & -.17 \\
\hline Lepitimating & -.05 & $-17 *+$ & $=14$ & -08 & -01 & $-.25=4$ \\
\hline Pressure & $-.23^{4}$ & $-.12^{* *}$ & -.06 & $-20^{*}$ & -.08 & -.17 \\
\hline
\end{tabular}

Note. The significance level for correlations was set at .01 (two-tailed test) for the larger samples and at .05 for the smaller samples.

$\star p<.05 \quad \star \star x<.01$ 


\section{References}

Ansari, M. A., \& Kapoor, A. (1987). Organizational context and upward influence tactics. Organizational Behavior and Human Decision Processes, 40, 39-49.

Bass, B. M. (1985). Leadership and performance beyond expectations. New York: Free Press.

Case, T, Dosier, L., Murkinson, G., \& Keys, B. (1988). How managers influence superiors: A study of upward influence tactics. Leadership and Organizational Development Journal. $9(4), \quad 25-31$.

Cohen, A., \& Bradford, D. (1989). Influence without authority: The use of alliances, reciprocity, and exchange to accomplish work. Organizational Dynamics, 17, 5-17.

Cohen, J., \& Cohen, P. (1983). Applied multiple regression/correlation analysis for the behavioral sciences. Hillsdale, NJ: Erlbaum.

Conger, J. A. (1989). The charismatic leader: Behind the mystique of exceptional leadership. San Francisco, CA: Jossey-Bass

Dosier, L., Case, T, \& Keys, B. (1988). How managers influence subordinates: An empirical study of downward influence tactics. Leadership and Organizational Development Journal, $9(5), 22-28$. 
Eagly, A., \& Chaiken, S. (1984). Cognitive theories of persuasion. In L. Berko witz (Ed.), Advances in experimental social psychology fVol. 17, pp. 267-359). San Diego, CA: Academic Press.

Erez, M., \& Rim, Y (1982). The relationship between goals, influence tactics, and personal and organizational variables. Human Relations, 35, 877-878.

Erez, M., Rim, Y, \& Keider, I. (1986). The two sides of the tactics of influence: Agent vs. target. Journal of Occupational Psychology, 59, 25-39.' '

Kanter, R. M. (1983). The change masters. New York: Simon \& Schuster.

Kaplan, R. E. (1986, Spring). Trade routes: The manager's network of relationships. Organizational Dynamics, pp. 3752 .

Kelman, H. C. (1958). Compliance, identification, and internalization: Three processes of attitude change. Journal of Conflict Resolution, 2, 51-60.

Keys, B., Case, T, Miller, T, Curran, K. E., \& Jones, C. (1987). Lateral influence in organizations. International Journal of Management, 4, 425-431.

Kipnis, D, \& Schmidt, S. M.(1988). Upward influence styles: Relationship with performance evaluations, salary, and stress. Administrative Science Quarterly, 33, 528-542. 
Kipnis, D, Schmidt, S. M., \& Wilkinson, I. (1980).

Intraorganizational influence tactics: Explorations in getting one's way. Journal of Applied Psychology, 65, 440452 .

Kotter, J. P. (1982). The general managers. New York: Free Press .

Liden, R. C, \& Mitchell, T. R. (1988). Ingratiatory behaviors in organizational settings. Academy of Management Review, 13, $572-587$

Mowday, R. T. (1978). The exercise of upward influence in organizations. Administrative Science Quarterly, 23. 137156.

Podsakoff, P, \& Schriesheim, C. (1985). Field studies of French and Raven's bases of power: Critique, reanalysis, and suggestions for future research. Psychological Bulletin, $97,387-411$

Schilit, W K., \& Locke, E. (1982). A study of upward influence in organizations. Administrative Science Quarterly, 27, $304-316$

Schmidt, S. M., \& Kipnis, D. (1984). Manager's pursuit of individual and organizational goals. Human Relations, 37, $781-794$

Schriesheim, C, \& Hinkin, T. R. (1990). Influence tactics used by subordinates: A theoretical and empirical analysis and 
refinement of the Kipnis, Schmidt, and Wilkinson subscales. Journal of Applied Psychology, 75, 246-257.

Stevenson, W, Pearce, J., \&. Porter, L. (1985). The concept of "coalition" in organization theory and research. Academy of Management Review, 10, 256-268.

Tedeschi, J. T, \& Melburg, V (1984). Impression management and influence in the organization. In S. B. Bacharach \& E. J. Lawler (Eds.), Research in the sociology of organizations (Vol. 3, pp. $31-58)$. Greenwich, CT: JAI Press. Tichy, N. M., \& Devanna, M. A. (1986). The transformational leader. New York: Wiley. Vroom, V.H., \& Jago, A.G. (1988). The new leadership: Managing participation in organizations. Englewood Cliffs, NJ: Prentice-Hall

Wortman, C. B., \& Linsenmeier, J. A. (1977). Interpersonal attraction and techniques of ingratiation in organizational settings. In B. M. Staw \& G. R. Salancik (Eds.), New directions in organizational behavior (pp. 133-178). Chicago: St. Clair Press.

Yukl, G. (1989). Leadership in organizations. Englewood Cliffs, NJ: Prentice-Hall.

Yukl, G. (1990). Skills for managers and leaders. Englewood Cliffs, NJ: Prentice-Hall. 
Yukl, G., \& Falbe, C.M. (1990). Influence tactics in upward, downward, and lateral influence attempts. Journal of Applied Psychology, 75, 132-140.

Yukl, G., \& Falbe, C.M. (1991). The importance of different power sources in downward and lateral relations. Journal of Applied Psychology, 76, 416-423.

Yukl, G., Falbe, C.M., \& Youn, J. Y. (in press). Patterns of influence behavior for managers. Group and Organization Management.

Yukl, G, Lepsinger, R., \& Lucia, T. (in press). Preliminary report on the development and validation of the Influence Behavior Questionnaire. In K. Clark \& M. Clark (Eds.), The impact of leadership. Greensboro, NC: Center for Creative Leadership. 